\title{
Systematic Research on Corporate Governance and Corporate Governance
}

\author{
Chang Liu ${ }^{1, \text { a }}$ \\ ${ }^{1}$ Shenyang University, Shenyang, Liaoning, China, 110000 \\ ${ }^{a}$ email,
}

Keywords: Corporate Governance, Corporate Governance, Systematic Research

\begin{abstract}
Enterprise produces not just their way of organizing these transactions more cost savings than the market, but companies in completion of the transaction at the same time be able to create new wealth. Respond to business contract is formed (beginning of governance) and contract enforcement and corporate management (governance beginning continuation and management) to make a distinction, which leads to a systematic rationale for the need of governance and management. Corporate governance and management are compared to strategic management as a link to build a systematic model of corporate governance and management.
\end{abstract}

\section{Introduction}

From the generation and enterprise development process point of view, a complete business system consists of two parts: First, when business is formed by means of the market to build corporate governance (Corporate Governance) level; the second is the direct promotion of their development after the formation of the enterprise the company management level. Reason for existence of the business, in the economic sense is nothing more than the satisfaction of creating wealth. In this process, in fact, it can also be investigated from two levels: First, the efficiency of resource allocation, that is, how efficient allocation of scarce resources of society. Enterprise and market are configuration of resources, but because of business generated in the market and continues to develop in the market, therefore, enterprise resource configuration belonging to configure resources at the level of the market. That is, the allocation of resources within the enterprise, then the configuration process after the market configuration. Content of corporate governance involved in the allocation of resources covers two processes: formation of companies is to establish the beginning and the foundation of corporate governance, enterprise resource reallocation process is reflected in the market mechanism of corporate governance structure and corporate governance of interactive process. Whether it is business or market, is not the purpose of the allocation of resources, the most fundamental lies in how to achieve full utilization of resources. The company management is more focused primarily on efficiency, but this is not to say that management does not involve the allocation of resources. More specifically, the allocation of resources under management concern is the basic framework of corporate governance conducted.

Company management is concerned with how best to achieve business goals, and corporate governance is to ensure that the implementation process is in line with corporate goals relevant subject interests. However, currently available literature, the vast majority are confined to one aspect while ignoring the systematic thinking on enterprise governance and management.

Enterprises as the core of the socio-economic system is facing a huge leap forward, the basic sign that information technology, knowledge accumulation and sharing of knowledge is characterized by the rise of the organization. Scarcity of enterprises of all kinds of resources relative shift occurs, and then the original enterprise internal and external challenges the basic framework, mainly in two aspects: First, the existing model of corporate governance generally by criticism, the US and UK mode because of its effectiveness and to take over the market, so that the board of directors for reform is growing, Japan and Germany mode crumbling in the financial crisis, people called for reform of its financial system, the relationship between government and enterprises and the relationship between Bank and so on; Second, enterprises in order to adapt to an increasingly 
competitive market environment, we must continue to adjust its management, but this will inevitably be subject to Corporate governance.

\section{The General Framework of Corporate Governance Models}

In the developed market economy, based on its corporate governance in different countries and diverse exhibits. With the development of the entire socio-economic system and information technology, corporate governance around the world we are faced with new challenges, but it is clear that it is in a transition stage. From the current mainstream model of corporate governance point of view, it can be divided into three categories: First, the United States and Britain as the representative of the external monitor mode. It reflects in large part as a shareholder sovereignty neoclassical model, the company's goal is to maximize the interests of shareholders. A framework for this purpose is "guaranteed by the combination of shareholder sovereignty corporate governance structure and competitive market to provide the shareholders." Second, Japan, Germany, representatives of the internal control mode, the guide is based on the interests of a wide range of relevant stakeholders on sovereignty. Accordingly, it is a prerequisite for the integration of all relevant stakeholders to ensure that the corporate governance model and people of this ideology. Third, as a representative of Southeast Asian family monitor mode. This model is based on the controlling shareholder of a family based on sovereignty, represented above. Conditions for the existence of its direct control of the family company's development, as well as the impact of traditional Confucian doctrine of the family. It is not difficult to see that the basic conditions for the three models built on in the process of economic transition in China, are not fully met, even very far. Obviously, if we do not choose, to mechanically copy to China, the result must be "in the form of the content of suffocation" or "departing from the content of the form" of corporate governance, it is difficult to play a good role. State-owned joint-stock transformation of the practice of Chinese enterprises in recent years, profound proof of this. As Aoki pointed out, in consideration of transition economies in corporate governance, we must recognize that the following two factors: (1) inherited from the planned economy as well as some of the conditions at the time of transition into existence, from the political and economic viable option limits the corporate governance transition process design; (2) neoclassical style shareholder sovereignty corporate governance model may not be the only effective solution.

\section{Related Research on Corporate Governance and Corporate Management}

The earliest of corporate governance and corporate management is distinguished professor Robert I.Tricker. His book on Governance 65 company clearly distinguish the importance of corporate governance and company management. Considered operating company management, and management is to ensure that the operator is on the right track [6] (P6). Kenneth N.Dayton specially conducted a detailed analysis that the corporate governance and corporate management both connections are different, are two sides of a coin, who can not be divorced who exist [7]. In Dayton opinion, corporate governance refers to the process of the board of directors use it to monitor the management, structure and contact management is that management establish goals and objectives to achieve action taken, he further believes that a company, the optimization company contact between the board and management is necessary. But they have no further analysis of its specific internal relations.

Corporate governance provides the basic framework for the whole network of business operations, the company management is to manage the enterprise toward the goals established in this framework. Lack of good governance of the company, even if / 0 good management system (in fact this is not possible), like a building foundation is not solid; similarly, there is no clear, simple model of governance management system only It could be a good blueprint, but the lack of actual content. However, we must note that this is the essential difference between the two concepts. From the ultimate goal, the company's governance and management are effective in order to achieve the creation of wealth, but each play is different levels of roles. Mainly on the corporate governance 
model is to divide responsibilities, and rights of all relevant stakeholders constitute among companies, as well as what means taken to achieve balance between each other, it is the business foundation of wealth creation and protection. Company management is the action in the established governance model, managers achieve the company's goal to take, which is the source of wealth creation and motivation. Connecting point between the two is that the company's strategic management level.

Western scholars on the relationship between corporate governance and corporate management, and is still mainly focused on the perspective of corporate governance. Although noting improvements in strategic management in an important position and role between the two, but not fully aware of the strategic management is actually maintain the fundamental link between corporate governance and corporate management. But maybe that Western scholars have ignored its inherent rational side. Because both in corporate governance or corporate governance, the West has experienced nearly 200 years of development, it has formed a relatively complete set of adaptive systems. Even if there were many problems in the corporate governance process, but because the whole system has been very mature market, the search for solutions on corporate governance has become an option from within the company. However, in China, companies just out of the planned economy, and the market system is far from perfect, whether it is corporate governance or management company are Chinese enterprises urgently need to be addressed.

\section{Matching of Corporate Governance and Corporate Management}

Demand for wealth is the source for enterprise system innovation. Governance and management are to achieve means to create wealth, the former performance-based institutional framework for the enterprise, the emphasis is the basis for target selection, that determines the target by the which the body, large who choose impact on the target, as well as checks and balances between them ; the latter is focused on the target itself, and the choice of the means to achieve their goals. In particular institutional environment, corporate governance and management requires coordination and cooperation.

In the pursuit of wealth, power, companies in the face of opportunities and challenges, through a clear own advantages and disadvantages, you can have three routes: One is the governance body intends to adjust and achieve change management mode by changing the governance structure, improve enterprise the purpose of efficiency; the second is the management body in order to enable enterprises to adapt to changes in external conditions and within their own interests to pursue, through guidance and adjustments to corporate strategy management mode, then change the corporate governance structure; the third is a combination of both.

\section{Systematic Study of Corporate Governance and Corporate Governance}

The fundamental nature of the business is that it is an effective mechanism for wealth creation, governance and management are all part of this effective mechanism constitutes a combination of both enterprise systems.

In modern enterprises, the governance structure of the general shareholders and other stakeholders (including employees and creditors) Board of Directors (Supervisory Board) and their elected general manager and other senior management personnel hiring constituted by the Board, and its focus is to achieve all relevant stakeholders responsibilities, and rights on the other, in particular, should be the responsibility of determining an appropriate framework and ensure that senior management innovation power are not infringed. Their internal governance mechanisms generally include: internal proxy battle (Internal ProxyFight), electoral rules and procedures of the board of directors, outside directors, CEO duality (CEO Duality), directors, supervisors and senior management personnel and compensation mechanisms stake. Mainly related to the rational allocation of rights, the symmetry of the distribution of information, the effectiveness of incentives and monitoring mechanisms. Clearly, the structure of corporate governance arrangements largely in thrall to its basic institutional environment in which, for example, the basic level of governance 
structure, stakeholder responsibility and rights and status of the parties in the governance structure of the relationship, as well as various nomination approval procedures. Furthermore, another constraint is that businesses can use external control mechanisms (such as mergers, takeovers and restructuring the market), which has a very close relationship with the level of economic development of a country and the macro-control policy adopted by the Government. Specific market governance mechanisms include: equity markets, credit markets, market manager, labor and product markets. Various means to form the corporate governance mechanisms are interrelated and influence each other.

Relations company as a legal entity, shareholders, creditors and companies, reflecting the capital markets; the operator, employee and customer aspects respectively showed the manager market, labor and product markets. It can be seen as a source of corporate governance in the interests of all actors, is closely associated with the market environment, improve the market environment will directly influence the mode of corporate governance. And the corresponding market is government behavior in corporate governance model selection process in the role. Depending on the model of economic development, there is a huge difference in the status and role of Governments in economic management. Government used its economic planning, industrial policy, fiscal and financial means of direct or indirect intervention in corporate governance mode selection. Corporate governance model and corporate governance structure as used herein, are two different concepts, which refers to the determination within the company among all relevant stakeholders and the status of the relationship between the legal framework, and does not include the market and other factors, it's just a former components. Corporate Governance Structure and Governance market mechanisms together to form a complete model of corporate governance.

The company management mainly cover strategic management, middle management and job management, since the surface management involves too broad, as well as taking into account the main strategic management and corporate governance are closely linked, so we focus from a strategic perspective, and analyze its corporate governance Relationship. Strategic management process generally consists of two parts: strategic planning and strategy implementation. The purpose of strategic management is to achieve the target enterprise system, which is based on the fundamentals of the entire enterprise is launched, the service for the whole enterprise, rather than as one participant (such as shareholders). The purpose of business is to create wealth management strategy is to achieve a better balance in the process of wealth creation long-term and short-term interests.

\section{Conclusion}

The corporate governance and corporate financial management in enterprise, which is connected with the market's performance in the factor market, the market system, intermediate products and final products market market constituted. Systematic relationship governance and management can be summarized as, at the enterprise level, as the basic governance framework sets out guiding principles and management, but in particular on the operational level, the microscopic activity management at the cumulative effect, would govern from to effect the adjustment.

\section{References}

[1] Cui Zhiyuan. Economic Research, Vol. 6 (2004) No 53, p.25-26

[2] Wang Qunyong. Foreign Economics and Management, Vol. 12 (2005) No 27, p.74-76

[3] Jing Jianfen, Hou XuSiem. Shanghai Economic Research, Vol. 30 (2004) No 19, p.144-145

[4] He Jun. Economic Research, Vol. 29 (2008) No 27, p.21-23

[5] Huang Yuncheng. China Industrial Economy, Vol. 8 (2003) No 27, p.57-60 